\title{
Bronchopulmonary dysplasia: old problem, new presentation
}

\author{
Eduardo Bancalari*
}

\begin{abstract}
The more common use of antenatal steroids, surfactant therapy and improved respiratory care has changed the presentation of bronchopulmonary dysplasia (BPD) originally described by Northway et al. in $1967 .{ }^{1}$ The severe form of BPD has been replaced by a milder clinical form that presents in infants who initially have no or mild respiratory distress syndrome (RDS). ${ }^{2}$
\end{abstract}

These infants respond to surfactant therapy and require prolonged mechanical ventilation because of apnea and poor respiratory effort. ${ }^{3-5}$ Thus, these infants have not been exposed to aggressive ventilation or high inspired oxygen concentrations, the two main factors traditionally invoked in the pathogenesis of the typical form of BPD. 6 This milder form of illness is the most commonly observed in extremely low birth weight infants today.

Once lung damage has occurred, these infants may require mechanical ventilation and increased oxygen concentration for long periods of time with gradual weaning from ventilator and oxygen therapy after several weeks or months. Infants with more severe BPD may still evolve into progressive respiratory failure, or even death, as a result of more severe lung damage and pulmonary hypertension that can result in cor pulmonale.

The reported incidence of BPD varies widely and this variation is related to differences in patient susceptibility and management, but inconsistencies in BPD definition also accounts for the variation. The diagnostic criteria for BPD are based on oxygen dependency and this can vary due to differences in altitude, the use of other methods of respiratory support such as continuous or intermittent positive airway pressure and use of drugs that can influence gas exchange, such as diuretics, respiratory stimulants or corticosteroids. Perhaps the major problem of using oxygen requirement to define BPD is the variation

* MD. Professor of Pediatrics. Director, Division of Newborn Medicine, University of Miami School of Medicine, Miami, USA.

Suggested citation: Bancalari E. Bronchopulmonary dysplasia: old problem, new presentation. J Pediatr (Rio J). 2006;82:2-3. in levels of oxygenation that are considered acceptable by different clinicians. ${ }^{7}$ To avoid the variability induced by this lack of established indication for oxygen therapy there is an ongoing effort to standardize the criteria for oxygen requirement. This physiologic test is based on arterial oxygen saturation measurements by pulse oximetry while infants are challenged with a lower inspired oxygen concentration. ${ }^{8}$

The incidence of BPD, defined as oxygen dependency at 36 wks postmenstrual age, in infants with birth weights between 500 and $1,500 \mathrm{~g}$ ranges between 3 and $43 \%$ in different centers of the NICHD Neonatal Research Network. ${ }^{9}$ Therefore the $24 \%$ incidence reported by NEOCOSUR falls within this range, although the diagnosis of BPD in this paper was based on oxygen need at 28 days. ${ }^{10}$ With increasing survival of extremely premature infants, the number of patients at risk for developing BPD increases. ${ }^{11}$ While the widespread use of antenatal steroids has essentially eliminated severe RDS in the more mature infants it has increased the survival of the more immature infants, those at higher risk of developing BPD. A similar situation has occurred with surfactant replacement therapy. Although, surfactant therapy is associated with decreased mortality due to RDS, it has not been shown to independently affect the incidence of BPD. However, when the combined endpoints, death and BPD are analyzed in relation to surfactant administration, the number of infants surviving without BPD has increased. ${ }^{12-14}$

Several epidemiological studies to identify the main risk factors that predispose extreme low birth weight (ELBW) infants to BPD have shown that after prematurity, the presence of a symptomatic patent ductus arteriosus (PDA) and systemic infections are associated with a significantly higher risk for BPD.2,15,16 The left-to-right shunting through the PDA produces an increase in pulmonary blood flow and in lung fluid, negatively affecting lung function and gas exchange, and consequently increases the risk for BPD. There is also compelling evidence that support the role of infection and inflammation in the pathogenesis of BPD. ${ }^{17-20}$ Increased neutrophil influx and 
cytokine activity in bronchoalveolar lavage fluid during the first days after birth have been associated with an increased likelihood of BPD in ventilator-dependent premature infants. The presence of systemic infection in the premature infant also adversely affects closure of the ductus, often inducing late ductal opening and failure to respond to medical treatment with Indomethacin. This is most likely due to the elevated serum level of prostaglandins and tumor necrosis factor observed in infants with infections. ${ }^{16}$ Although prophylactic closure of the ductus with Indomethacin shortly after birth is not associated with a reduction in the incidence of BPD, the strong association between duration of a symptomatic PDA and BPD suggest that a prompt pharmacological or surgical closure of the symptomatic ductus plays an important role in the prevention of BPD. The same is true for nosocomial infections that are emerging as an important factor in the pathogenesis of BPD.

The article from the NEOCOSUR collaboration ${ }^{10}$ describes the result from a large epidemiological study to identify some of the risk factors associated with the development of BPD in very low birth weight infants in South America. In this study the authors confirm the significant role of gestational age and birth weight, gender, the presence of a PDA, and postnatal infections in the pathogenesis of BPD. The definition of BPD in this study was based on oxygen requirement at 28 days and at 36 weeks corrected age but it is not clear if the diagnostic criteria required continuous oxygen exposure during these periods of time or only at these two specific time points. This can have a remarkable influence on the incidence of BPD. ${ }^{3}$ The reported association between necrotizing enterocolitis (NEC) and an increased risk of BPD is interesting and has not been described before. NEC is usually associated with a severe systemic inflammatory reaction and deterioration in respiratory function. It is therefore not surprising that this may increase the risk of BPD the same way sepsis increases it.

Important questions that remain unanswered regarding the pathogenesis and prevention of BPD include the specific mechanisms for the decreased alveolar and capillary formation observed in these infants. It is also not clear what is the mechanism for the progressive deterioration in lung function that is frequently observed in ELBW infants after the first few days after birth. The mechanisms by which the persistence of the ductus arteriosus and systemic infections increase the risk of BPD are also not well understood. The results of this study from NEOCOSUR are very relevant and emphasize the importance of preventing a prolonged PDA and nosocomial infections as ways of reducing the incidence and severity of BPD in susceptible infants.

Unfortunately BPD is clearly the result of multiple factors that can negatively influence the development of the immature lung. For this reason it is unlikely that we will be able to significantly reduce its incidence as long as extremely premature infants continue to survive at increasing rates.

\section{References}

1. Northway WH, Rosan RC, Porter DY. Pulmonary disease following respiratory therapy of hyaline membrane disease. Bronchopulmonary dysplasia. N Engl J Med. 1967;276:357-68.

2. Rojas MA, Gonzalez A, Bancalari E, Claure N, Poole C, Silva-Neto G. Changing trends in the epidemiology and pathogenesis of neonatal chronic lung disease. J Pediatr. 1995;126:605-10.

3. Bancalari E, Claure N, Sosenko IRS. Bronchopulmonary Dysplasia: changes in pathogenesis, epidemiology and definition. Semin Neonatol. 2003;8:63-71.

4. Charafeddine L, D'Angio CT, Phelps DL. Atypical chronic lung disease patterns in neonates. Pediatrics. 1999;103:759-65.

5. Collaborative European Multicenter Study Group: surfactant replacement therapy for sever neonatal respiratory distress syndrome: an international randomized clinical trial. Pediatrics. 1990;82:683-90.

6. Palta M, Gabbert D, Weinstein MR, Peters ME. Multivariate assessment of traditional risk factors for bronchopulmonary dysplasia in very low birth weight neonates. J Pediatr. $1991 ; 119: 285-92$.

7. Ellsbury DL, Acarregui MJ, McGuinness GA, Klein JM. Variability in the use of supplemental oxygen for bronchopulmonary dysplasia. J Pediatr. 2002;140:247-9.

8. Walsh M, Wilson-Costello D, Zadell A, Newman N, Fanaroff A. Safety, reliability and validity of a physiologic definition of bronchopulmonary dysplasia. J Perinatol. 2003;23:451-6.

9. Lemons JA, Bauer CR, Oh W, Korones SB, Papile LA, Stoll BJ, et al. Very low birth weight outcomes of the National Institute of Child Health and Human Development Neonatal Research Network, January 1995 through December 1996. Pediatrics. 2001;107:E1.

10. Tapia JL, Agost D, Alegria A, Standen J, Escobar M, Grandi C, et al. Bronchopulmonary dysplasia: incidence, risk factors and resource utilization in a very low birth weight infant SouthAmerican population. J Pediatr (Rio J). 2006;82:15-20.

11. Parker RA, Pagano M, Allred EN. Improved survival accounts for most, but not all of the increase in bronchopulmonary dysplasia. Pediatrics. 1992;90:663-8.

12. Jobe $\mathrm{AH}$. Pulmonary surfactant therapy. $\mathrm{N}$ Engl J Med. 1993;328:861-8.

13. Kendig JW, Notter RH, Cox C, Aschner JL, Benn S, Bernstein RM, et al. Surfactant replacement therapy at birth: final analysis of a clinical trail and comparisons with similar trials. Pediatrics. 1988;82:756-62.

14. Schwartz RM, Luby AM, Scanlon JW, Kellog RJ. Effect of surfactant on morbidity, mortality, and resource use in newborn infants weighing 500 to $1500 \mathrm{~g}$. N Engl J Med. 1994;330:1476-80.

15. del Moral T, Claure N, Van Buskirk S, Bancalari E. Duration of patent ductus arteriosus as a risk factor for bronchopulmonary dysplasia. Pediatr Res. 2001;49:282A.

16. Gonzalez A, Sosenko IRS, Chandar J, Hummler H, Claure N, Bancalari $E$. Influence of infection on patent ductus arteriosus and bronchopulmonary dysplasia in premature infants $<1000 \mathrm{~g}$. J Pediatr. 1996;128:470-8.

17. Groneck P, Gotze-Speer B, Oppermann M, Eiffert H, Speer CP. Association of pulmonary inflammation and increased microvascular permeability during the development of bronchopulmonary dysplasia: a sequential analysis of inflammatory mediators in respiratory fluids of high-risk preterm neonates. Pediatrics. 1994;93:712-18.

18. Pierce MR, Bancalari $E$. The role of inflammation in the pathogenesis of bronchopulmonary dysplasia. Pediatr Pulmonol. 1995; 19:371-8.

19. Watterberg KL, Demers LM, Scott SM, Murphy S. Chorioamniotis and early lung Inflammation in infants in whom bronchopulmonary dysplasia develops. Pediatrics. 1996;97:210-5.

20. Yoon BH, Romero R, Jun JK, Park RH, Park JD, Ghezzi F, et al. Amniotic fluid cytokines (interleuking-6, tumor necrosis factoralpha, interleukin-1 beta, and interleukin -8) and the risk for the development of bronchopulmonary dysplasia. Am J Obstet Gynecol. 1997;177:825-30. 